\title{
Multiple Modality in the Lallans Territory: Current Vernacular (Un)acceptability of the Syntax of Modal Combinations in South-Eastern Scotland
}

Anthony R. Bour*

\begin{abstract}
This paper has the purpose to provide a greater understanding of the current use of the syntax of Multiple Modals (MMs) also known as Modal Combinations in the Southern part of Scotland. A series of 8 clauses, each containing one particular combination, is proposed in order to determine the acceptability of these combinations or their potential replacement with alternative constructions. The type of sentence written, the current dialectal knowledge of the respondents, and their grammatical preferences will shed the first light on the level of stability of these vernacular constructions on the ancestral territory of MMs in which only very few field surveys have been conducted to date.
\end{abstract}

Key words: combinations, modals, syntax, semantics, Scottish English, dialects

* Hermann Paul School of Linguistics, Freiburg im Breisgau, bour.anthony1@orange.fr 


\section{Introduction}

Multiple Modality is not a new dialectal phenomenon in the Western part of the Englishspeaking world. The number of combinations created via the assembling of different modal expressions (Quirk 1985) remain quite important. Dialectal properties of Multiple Modals (MMs) have regularly been considered as a problem for prescriptive linguists such as Chomsky:

The English double modal auxiliaries such as might could pose significant problems for most formal syntactic theories, from Chomskyan generative varieties (e.g., Government-Binding theory) to phrase-structure grammars (e.g., Generalized Phrase Structure Grammar). [...] In the Generalized Phrase Structure Grammar approach, the English modals are heads of a V projection [...] In both theories, then,modal combinations are essentially ruled out. (Nagle 1995, 207)

This dialectal phenomenon does not have its place in all of the Standard English varieties in which only one modal represents the head of the clause. Diachronically speaking, combinations of modals already existed in Old English and Middle English. The difference resides in the grammatical identities of these combinations designated as doubleverbs or pre-modal entities. It resulted in divergences in the historical analysis of Double Modals (DMs) and Triple Modals (TMs), especially with the Visser/Nagle opposition. Visser (1963-1973) claims that these early verbal combinations represent the original roots of present-day MMs before the modals we know became auxiliaries at the end of the $15^{\text {th }}$ and early $16^{\text {th }}$ centuries.

Visser claims that modal combinations were frequent in Middle English, and indeed at least shall may was. Thus, one might look for a gradual development of the current double modals from combinations of verbs before reanalysis to combinations of auxiliaries afterward. (Nagle 1989, 365)

Nagle prefers creating two unrelated developments of modal combinations, MMs as verbal combinations belonging to former varieties of Old and Middle English and MMs as auxiliary combinations that first appeared in the $18^{\text {th }}$ century in Southern Scotland:

The historical home of the current double modals would appear to be in Scotland and Scots English. (Nagle 1995, 209)

These latter combinations continue to undergo syntactic and semantic modifications with the arrival of Scotsmen and women in the American South from 1718 onwards. What is more, the earliest attestations of Scottish modal combinations, will can and 
may can, were discovered in Scottish texts drafted by Calderwood and Alexander Ross in 1756 and 1768 respectively:

(a) If we get a German doctor, not one of us will can speak to him. (1756)

(b) The youth himself may can to rule the rost. (1768)

However, Old English structures like moste or moston agan, (must ought in Scottish English) and sceal agan, sceall cunnan (should ought and should can in Scottish English dialects of the Lowland area) (Nagle 1989, 366) were detected in previous writings of the Early Middle Ages. Despite their grammatical differences, the morphological resemblance of these former and modern modal combinations cannot, for the time being, confirm a complete historical disconnection. More research in diachronic linguistics as regards this dialectal phenomenon in connection with the history of English modals needs to be pursued in order to get clearer answers on this matter.

The theories that have emerged since the 1970s (Butters 1973) have regularly underestimated the complexity of these vernacular constructions by mainly focusing on a limited series of modal combinations composed of two modals and termed Double Modals (DMs). The first modal takes the epistemic meaning while the second one takes the root meaning:

Might could, might can, might would, might should, will can, would can, should can.

This short list is just the tip of the iceberg. The reality of this dialectal system presents many more combinatorial possibilities, syntactic and semantic orderings, and spelling variants which are less spoken and written by Anglophone natives than those listed above. The combination written in bold nicknamed the "queen of combinations" (DeLa-Cruz 1995, 82) is used in every Anglophone location where multiple Modality is present. Nevertheless, the usage of most of these other structures is still far from disappearing. They are simply used in more local areas. Amazing lists of combinations were diagnosed by Montgomery (1994), Di-Paolo (1989), De-La Cruz (1995), Battistella (1995) and Nagle $(1994,1997)$ Furthermore, most of the studies remained focus on the Southern United States, where there is a majority of Americans of Scotch-Irish origin. They brought these constructions with them when they arrived in the New World between 1718 and 1775 (Montgomery and Mishoe 1994, 19).

Two independent developments of Multiple Modality have been existing since this period. The grammatical-syntactic rules in the positions, types, and meanings of modals are not the same any more in both countries. Only a minority of researchers, such as Brown (1991), Miller and Brown (1982), Millar and Brown (1980) and Nagle (1989, $1994,1995,1997)$ have tried to give a first glimpse of the syntactic and semantic understanding of DMs and TMs in the place where they originated, i.e. Southern Scotland. Although they brought very interesting data from this first research as regards the current use of these combinations in Hawick and the Lothians, no further studies were 
carried out in the following years. The latest field survey took place in 1989 by Keith Brown in Hawick. Twenty years later, I wanted to carry out a new one-month field survey in the region where everything started, i.e. the Scottish Borders.

\section{Field Survey}

From April $18^{\text {th }}$ to May $23^{\text {rd }}$, 2011, I conducted a dialectal study in four towns of the Scottish Borders region. Below are indicated the names of the four towns as well as the counties to which they belong:

Kelso, Jedburgh and Melrose: county of Roxburghshire

Coldstream: county of Berwickshire

In total, 73 structured-type questionnaires were distributed over the period of 5 weeks, 46 of which were completed by women and 27 by men. Also concerning the age group, 27 of 46 women were aged between 40 and 60 years, whereas for men, 21 of 27 who accepted to answer the questionnaire were aged between 30 and 70 years. Severall of these respondents did not come from Scotland but already knew these constructions before working and living in the Scottish Borders, since this dialectal phenomenon is also spoken in Cumberland and Northumberland, two counties located in Northern England.

As mentioned above, this questionnaire was created based on a structured approach. This approach allows for the preparation of questions that are termed in the jargon of social sciences as closed and semi-closed questions. This methodology is especially recommended by the French sociolinguists Calvet and Dumont (1999):

La plupart des chercheurs préfèrent élaborer un questionnaire structuré comprenant à la fois des questions fermées et semi fermées, plutôt qu'un questionnaire composé uniquement de questions ouvertes. (Calvet et Dumont 1999, 18)

Most researchers prefer preparing a structured questionnaire comprising both closed and semi-closed questions, rather than a questionnaire only made up of open questions. (Calvet and Dumont 1999, 18) (English translation by the author Anthony R. Bour) 
A closed question consists of the informant simply answering yes or no to a series of two written questions. This represents the first task of the questionnaire:

\begin{tabular}{llcc}
\hline 1 & $\begin{array}{l}\text { Have you ever heard the type of structure underlined below? } \\
\text { He'll can help us the morn. }\end{array}$ & $\mathrm{Y}$ & $\mathrm{N}$ \\
\hline 2 & Would you use it yourselves in a similar context? & $\mathrm{Y}$ & $\mathrm{N}$ \\
\hline
\end{tabular}

If the respondents answer no to the second question, they have to replace it with a grammatical construction that can be similar but not necessarily equal to the combination that, according to him/her, would fit better with the clause.

In semi-closed questions, the respondents have to select one grammatical feature among four proposed options. This represents the second task of the questionnaire

I didn't tak them at aa.
A/ uisst tae could
B/ used to would
C/ use tae could
D/ used to could
E/ another similar construction

This paper will focus on the first task in which respondents have the possibility to replace the modal combination proposed in the clause by another construction of his/her choice. It can be either another vernacular construction different or not from an MM or a Standard English construction. By proposing this introductory task, the purpose of this study is also to analyse the progression of the standard or other vernacular constructions different from MMs in a typical Southern Scottish territory in which the Scots language and Scottish-English dialects are still alive. The eight sentences that are proposed contain combinations that some Scottish-(English) respondents may never use, but it does not necessarily mean that their knowledge and use of Multiple Modality is limited. This dialectal phenomenon is so complex and rich that grammatical preferences in the syntax of MMs must automatically be taken into account in such dialectal studies. Here are the eight sentences: 
(1) I know I might could and should enjoy myself.

(2) He willnae can come.

(3) He'll can help us the morn.

(4) I was afraid you might couldn't find this address.

(5) A good machine clipper would could do it in half a day.

(6) I think that we should have ought've done that yesterday.

(7) He wouldn't could've worked, even if you had asked him.

(8) He should can go tomorrow.

I will start by showing two tables summarising the initial reactions of the respondents. The first table contains a not insignificant number of respondents who maintained that they know and would use the DMs in most of the eight sentences. The second table will show the contrary. It is quite striking because you find two radical sides in these four towns, i.e. people who recognise and use most of the combinations proposed in this first task and the exact opposite, privileging the standard in which only one modal auxiliary is allowed in the English clause. Intermediate behaviours are rare.

\begin{tabular}{lcccc}
\hline 2011 & \multicolumn{2}{c}{$\begin{array}{l}\text { Have you ever heard this } \\
\text { kind of structure? }\end{array}$} & $\begin{array}{l}\text { Would you use it yourselves } \\
\text { in a similar context? }\end{array}$ \\
\hline \hline & M & W & M & W \\
\hline might could and should & 8 & 23 & 6 & 18 \\
willnae can & 13 & 36 & 7 & 14 \\
'll can & 12 & 29 & 7 & 19 \\
might couldn't & 6 & 14 & 3 & 6 \\
would could & 5 & 19 & 3 & 9 \\
should have ought've & 12 & 17 & 7 & 9 \\
wouldn't could've & 10 & 20 & 6 & 14 \\
should can & 11 & 25 & 8 & 17 \\
\hline
\end{tabular}

Table A: Informants who answered both questions positively

Table A above shows the number of respondents who actually use these DMs in dayto-day conversations as well as those who have asserted to have heard these kinds of constructions among their friends, family members, or co-workers. Similar to Hawick, willnae can, 'll can as well as should can remain the most recognisable combinations in Kelso and Jedburgh, especially among female speakers. Might could and should is also heard and used orally quite often among the female respondents, while men seem to be less familiar with these constructions. The other DMs of the table are only used from time to time and are not recognisable from most speakers. It is necessary to recall that since Kelso and Jedburgh are defined as less local towns, i.e. adopting more Standard Scottish English features than Hawick, the number of people, especially male 


\begin{tabular}{lcc}
\hline 2011 & Have you ever heard this kind of structure? \\
\hline \hline & M & W \\
\hline might could and should & 18 & 20 \\
willnae can & 13 & 6 \\
'll can & 14 & 13 \\
might couldn't & 20 & 28 \\
would could & 21 & 22 \\
should have ought've & 14 & 25 \\
wouldn't could've & 16 & 21 \\
should can & 15 & 18 \\
\hline
\end{tabular}

Table B: Informants who answered the first question negatively

respondents, who responded negatively to both questions remains higher than expected, as table B shows. Nonetheless, a certain number of vernacular constructions is still maintained and continues to change morphologically, orthographically, and semantically speaking. The following sections of this paper will present the diverse standard and vernacular structures proposed by the respondents, replacing the MMs indicated in the eight sentences. The brackets after each sentence represent the number of respondents who proposed their alternative to the MM combination. When there is no bracket, the structure of replacement was proposed just once. 


\section{Structures of replacement}

\begin{tabular}{ll}
\hline Standard structures & Vernacular structures \\
\hline \hline I know I should enjoy myself (14) & I know I could but I wouldne \\
I know I could and should enjoy myself (3) & \\
I know I might enjoy myself (3) & \\
I know I may enjoy myself (2) & \\
I know I might and should enjoy myself (2) & \\
I know I will enjoy myself (2) \\
I know I might, could and should enjoy myself \\
I know that I could, and should, enjoy myself \\
I know I do enjoy myself \\
I know I could enjoy myself \\
I know I could, and ought to, enjoy myself \\
I know I will enjoy myself \\
I know it will be good fun \\
I could but should I \\
I know I probably should enjoy myself \\
I know I should enjoy it \\
I know I would and should enjoy myself \\
I know I can enjoy myself \\
I know I do enjoy myself and life \\
I know I might conceivably enjoy myself \\
I will go, but, might not enjoy it! Probably I would though!
\end{tabular}

Table 1: I know I might could and should enjoy myself.

The dominant presence of standard constructions proposed by the informants is relatively recognisable in this first table. There is one exception in which one man added a non-standard Scottish negator ne, i.e. not in Standard English. A great number of standard structures were proposed, especially those which contain the Central Modals (Quirk 1985, 137) could, should and might. Should is the most appropriate modal that was kept in the syntax by Scottish Borders' respondents. Should was maintained by five women and nine men. Other respondents wanted to separate the modals of the combination by the conjunction of coordination and, which looks as follows:

$$
\text { Might and should would and should could and should. }
$$

Again, we find should in this situation always positioned after the conjunction. The other conjunction, but, was also proposed by some respondents, therefore separating the two modals of the combination as well. It is difficult to determine at this point if 
they still identify these structures as MMs. Is it even mainstream for them? More enquiries of this kind need to be carried out to obtain further clarification in this regard.

\begin{tabular}{ll}
\hline Standard structures & Vernacular structures \\
\hline \hline & He willnae come (4) \\
He won't come (12) & He cannae come (4) \\
He won't be able to come (8) & He winnae can come \\
He will not come (6) & He'll not can come \\
He can't come (3) & He will not can come \\
He cannot come (2) & He'll no be able to attend \\
He'll not come & He winna come \\
He will not be able to come & He will no be able to come \\
He wouldn't come & He wouldne come \\
He will come & \\
He won't be there & \\
He is unable to come & \\
\hline
\end{tabular}

Table 2: He willnae can come.

Unlike the first table, it is very interesting to notice the astonishing diversity of vernacular structures of replacement proposed by Scottish-English respondents as regards the DM willnae can. In total, ten different dialectal structures were written. At the outset of the table, one woman contracted will, followed by the standard negation not instead: ll not can.

Two other women had the same attitude and preferred keeping the DM with slightly different modifications. One proposed winnae can which implies a change in the spelling of will due to its attachment with the Central Scots negator nae. Here we can see a spelling and a morphology quite different from the mainstream construction will not. Susan Rennie and Matthew Fitt (1999) draw up a great number of spelling variants in regard to the negation with modals in Scots vernacular dialects:

Insteid o willna (or willnae), or wullna (or wullnae), ye'll sometimes get winna (or winnae) or wunna (or wunnae). (Rennie 1999, 10)

On the contrary, the other woman proposed a more standard spelling variant by writing will not can. Separating the negator from the first modal generates an alternative meaning in the sentence. From he winnae can come (he won't be able to come) to he will not can come (he will be able not to come).

In the first paraphrase we are dealing with an impossible task to realise in the future whereas in the second paraphrase, the person has the possibility to choose to come or not. In Multiple Modality theories, the position of the negator in a DM or TM is very important because it regularly determines the meaning of the entire sentence. 
Also, it depends on the morphosyntactic and semantic behaviour of the respondent. In these two variants, it may be considered as one single semantic interpretation for both women. Their level of knowledge of this dialectal phenomenon must also be taken into account in such studies.

Most of the time, people tend to preserve will or one of its spelling variants over can. Concerning male speakers, six of them chose to write a vernacular structure of replacement. To create this, they deleted can but not will, which gives interesting writings, such as "winna come" and "willnae come". Na is a more traditional Southern Scots negator while nae is identified as a modern vernacular Central Scots negator. Wudne is the translation of wouldn't in Standard English and one man in particular included a Semi Modal or, in Quirk's $(1985,13)$ terminology a "Semi Auxiliary", which is be able to after the vernacular negative no. Can was replaced by this modal expression. "Willnae come" is common to both genders when they use different varieties of Scots. This assembling of will + nae has regularly been observed in previous studies on vernacular modality in the Lowland Scots area, even in the survey conducted about the Multiple Modality system in the traditional Hawick Scots vernacular (Bour 2010).

Although the number is slightly reduced, there are still more respondents, especially women, who proposed to write modal structures applying the normative rules of the English language. 24 women and 13 men indicated standard modals in the questionnaire. Won't was the most written modal by seven women and five men. Seven other women also preferred to associate won't with the semi modal be able to, which was not the case for men. As regards both genders, there were very few who wrote "he can't come" and "he cannot come", a result that is different to the Hawick study (Bour 2010). Furthermore, the DM won't can was not proposed in the 2011 study, unlike in the Hawick 2010 study. It shows that tendencies in the use of standard and non-standard modal structures are never the same from place to place, even when they are close together, and that each local and regional town keeps its own habits in terms of dialectal heritage. However, some of these habits are undergoing modifications as time goes on. 


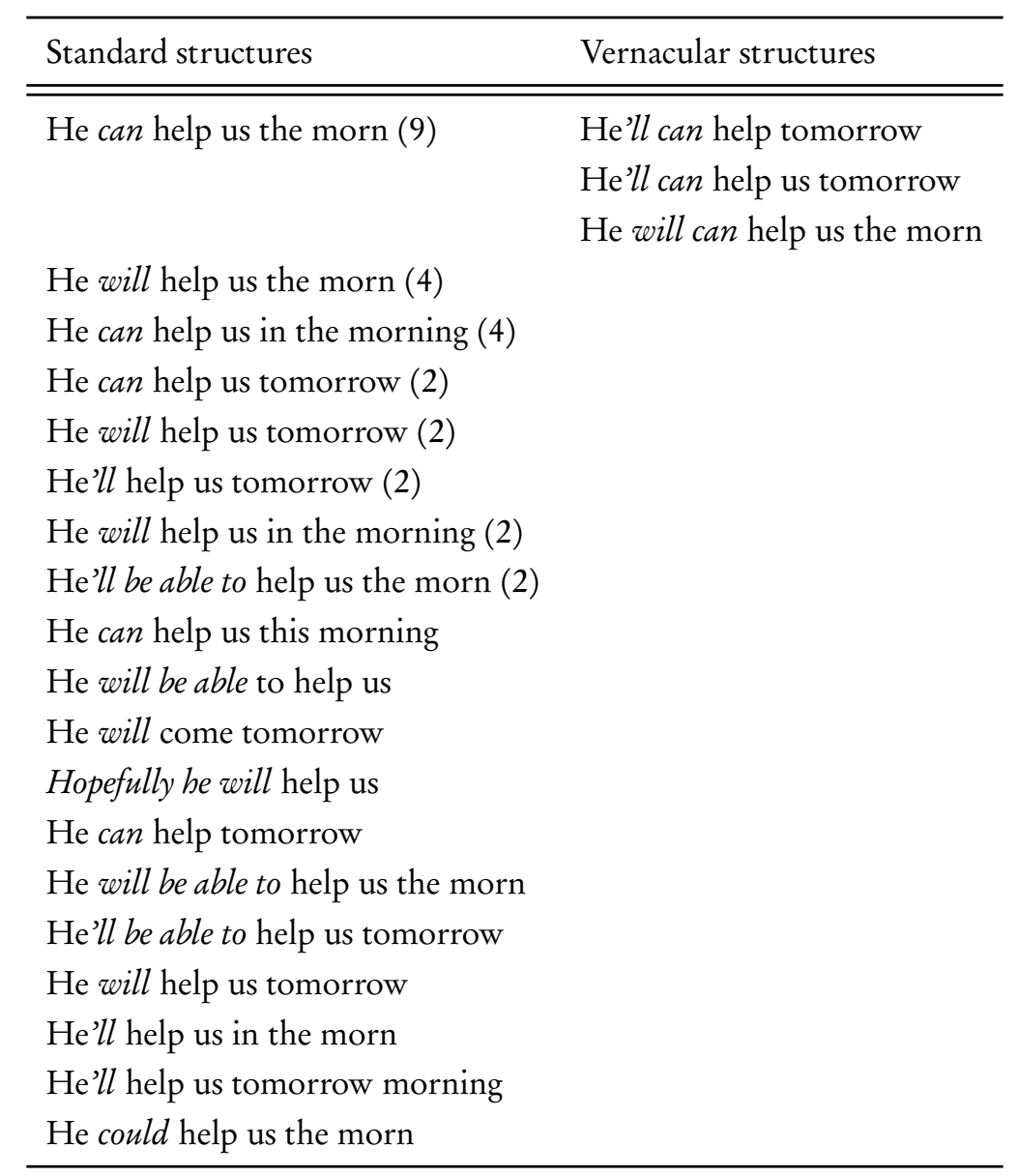

Table 3: He'll can help us the morn.

Table 3 shows the same DM without the negation and a contraction of the first modal. With these modifications, it can already be noticed that most respondents replaced the DM with standard constructions. Unlike the previous table, there are only three vernacular propositions, all written by women. The presence of the Scottish negator in the second sentence inserted between both modals can generate some more Scots interpretations from a greater part of the respondents. For the moment, however, this remains a hypothesis that still needs to be proven.

In the selected standard clauses, most female informants chose will instead of can which, like in the second table, shows that the epistemic sense of futurity is more important for these respondents than the root sense of ability expressed by can. Four of them also added be able to with will. Eight male respondents reacted differently by giving priority to the Central Modal can instead of will. Seven of them selected will and only one proposed could. There are two grammatical analyses for could in this clause: 
Either the past tense prevails and the clause means that the person will not be able to help them:

(3a) He could help us the morn but asserted that he does not (or will not) have time.

Or the conditional is dominant and, thus, there is the probability that he may help us or not:

(3b) He could help us the morn. I am going to ask him.

The next clause contains the most common DM spoken and written in the Englishspeaking world, the so-called 'queen of combinations', might could, in the negative.

\begin{tabular}{ll}
\hline Standard structures & Vernacular structures \\
\hline \hline I was afraid you might not find the address (9) & I was afraid you might couldnae find the address (2) \\
I was afraid you couldn't find the address (8) & I was afraid you couldnae find the address (2) \\
I was afraid you wouldn't find the address (5) & I was afraid you could nae find the address \\
I was afraid you might not be able to find the address (4) & I was afraid you maybe no be able to find ... \\
I was afraid you wouldn't be able to find the address (4) & I was afraid you might not can find the address \\
I was afraid you may not find the address (3) & I was afraid you wouldnea find the address \\
I was afraid you would not be able to find the address (3) & \\
I was afraid you mightn't find the address (2) & \\
I was afraid you maybe couldn't find the address (2) & \\
I was afraid you would not find the address & \\
I was afraid you won't find the address & \\
I was scared you couldn't find the address & \\
I was afraid you could not find the address & \\
I was afraid you cannot find the address & \\
I was afraid you might find the address & \\
I was worried you wouldn't find the address &
\end{tabular}

Table 4: I was afraid you might couldn't find this address

Most standard constructions of replacement provided by seven female respondents contain a single modal in the negative might not. Couldn't was the favourite Central Modal that replaced the DM. Female respondents insisted on the epistemic meaning of might, 
whereas male informants preferred emphasising the impossibility of realization of the action. Two different paraphrases emerge from these meanings:

Female speaker interpretation:

(4a) It might not have been possible for you to find the address, which worried me.

Male speaker interpretation:

(4b) It was impossible for you to find the address, which worried me.

Regarding vernacular interpretations, five women and three men proposed more regional structures. Two women kept the DM by turning the Standard English negator not into the Central Scots enclitic negator nae. One man kept not and put it between might and the present of could, i.e. can.

Coulnae alone was proposed by two women and one man for this clause. Another woman proposed the variant could nae, in which the wide scope negator is detached from the Central Modal. Since it is a sentential negator, it should not be detached from its auxiliary, according to the Scottish English negative system (Brown 1991, 80-81). Nevertheless, this syntactic possibility is commonly found in the North-Eastern Scots dialect called Doric. A few examples written in Buchan Doric show this detachment of the sentential negator with primary auxiliaries be, have and $d o$ :

(a) There wis nae English-speakers. (McClure 2002, 54)

(b) They had nae parental attitudes til it. (McClure 2002, 60)

(c) It's nae's just nae the same ye know. (McClure 2002, 68)

(d) Dae ye nae spik aboot your beets? (McClure 2002, 76)

(e) There'll be nae discussion. (McClure 2002, 194)

(f) I'm nae mista'en. (McClure 2002, 195)

(g) You're nae gan near me wi' yoghurt! (McClure 2002, 200)

Nae could be replaced by the narrow scope negator no in each of the seven sentences above. Without affecting the meaning of the clauses. The situation would, however, be different if nae or no would be inserted in one or several modal expressions.

This common type of Scots negator is regularly present in Kelso and Jedburgh, which is quite striking because both towns are just a couple of miles from Hawick and are still very different from this local town in terms of dialect. Hawick is still very connected with traditional Broad Scots, containing different negators that, in the 2010 Hawick study, were still detected as being used with this same modal, i.e. couldny and couldni. Distance between towns of the Scottish Borders does not seem to bring about a homogenisation of all the Southern Scots dialects.

Unlike the others, this fifth table is very short, due to a lack of structures of replacement. Most respondents removed either would or could in the DM. Would is the most favourite Central Modal for both genders in this clause. The Semi Modal be able to was again suggested by the respondents to replace the second modal of the combina- 


\begin{tabular}{ll}
\hline Standard structures & Vernacular structures \\
\hline \hline A good machine clipper would do it in half a day (22) & \\
A good machine clipper could do it in half a day (17) & \\
A good machine clipper would be able to do it in half a day (7) \\
A good machine clipper could do it better \\
A good machine clipper will do it in half a day \\
A good machine clipper might be able to do it in half a day \\
A good machine clipper will be able to do it in half a day \\
A good machine clipper would have been able to do it in half a day \\
A good machine clipper would do it better
\end{tabular}

Table 5: A good machine clipper would could do it in half a day.

tion. Would could is a North-Eastern English DM which might explain the reason why only standard constructions of replacement were proposed, although there have always been deep cultural connections between the Scottish Borders and Northumberland. The present of would could, i.e. will can remains the typical Scottish-English combination of the Lallans territory that for many European Anglophone speakers of MMs is still irreplaceable.

\begin{tabular}{ll}
\hline Standard structures & Vernacular structures \\
\hline \hline I think that we should have done that yesterday (35) & We shoulda done that (2) \\
I think that we should 've done that yesterday (3) & We ought've done that (2) \\
I think that we shouldn't have done that yesterday (2) & We should have ought'tae done that \\
I think that we should have done it yesterday (2) & We should done that \\
I think that we ought to have done that yesterday (2) & We ought have done that \\
I think that we should not have done that yesterday & \\
I think that perhaps they should have done that yesterday & \\
\hline
\end{tabular}

Table 6: I think that we should have ought've done that yesterday.

The most standard structure of replacement is the traditional should have + past participle, mentioned 35 times in the questionnaires. Ought to bave + past participle, which remains a very old-fashioned modal structure with or without the have-auxiliary, was only written twice.

As regards vernacular structures, the to of ought to was deleted, which does not change the meaning of the clause. Furthermore, the have-contraction in 've next to ought and a attached to should, were proposed by both genders and the have-deletion was proposed by only one female respondent, which implies a past participle located after the modal auxiliary (should done). All these grammatical morphemes represent a simplification 
or levelling processes that are not colloquial features in modern non-standard Scottish English dialects. Only one female respondent suggested a slight modification in the DM by turning the second have, 've, into 'tae.

The next DM contains the modal would accompanied by a contracted negative, followed by could with a contracted have.

\begin{tabular}{ll}
\hline Standard structures & Vernacular structures \\
\hline \hline He wouldn't have worked, even if you had asked him (21) & \\
He could've worked, even if you had asked him (5) & He wouldnae work, even if you had asked him \\
He would not have worked, even if you had asked him (3) & He couldnae have worked, even if you had asked him \\
He couldn't have worked, even if you had asked him (3) & He couldnae work, even if you had asked him \\
$\begin{array}{ll}\text { He could not have worked, even if you asked him (3) } \\
\text { He wouldn't have been able to work, even ... (2) }\end{array}$ & He wouldnea be able tae work, even ... \\
He would've worked, even if you had asked him (2) & He wouldn't worked, even if you had asked him \\
He wouldn't be able to work, even if you had asked him & \\
He was unable to work, even if you had asked him & \\
He couldn't work, even if you had asked him & \\
He wouldn't work, even if you had asked him & \\
\hline
\end{tabular}

Table 7: He wouldn't could've worked, even if you had asked him.

In this table, most respondents decided to write mainstream structures of replacement. Regarding their grammatical preferences, 18 women and 12 men preferred deleting could and keeping would with or without the perfect infinitive have + V-ed and with or without a negative particle. Very few proposed a vernacular interpretation of the clause by replacing not by Central Scots negator nae or nea attached to either modal. The observation made in Hawick (Bour 2010) again shows the differences in the spelling of the negator. For the same clause, a 20 -year-old woman from this town proposed a typical Broad Scots version of replacement:

(7a) He wouldny of worked even if you asked him.

As said previously, some Scottish dialectal features are spoken and written in limited geographical and administrative areas of the Borders. Such features, like $n y$ or $n i$, can already sound very strange for Scotsmen and Scotswomen residing and working nearby the Hawick administrative area. Similar situations can be found for MMs as well, but it will be more interregional rather than between counties of a same region, due mainly to the length and morphological complexity of the combinations.

In this last clause, only one non-standard structure was proposed by one female respondent. The DM of this clause was preserved, whereas the spelling of the main verb and the time marker was slightly changed. The morn or the morrow are the favourite Scots spellings for tomorrow unlike the morin. This spelling must belong to a very spe- 


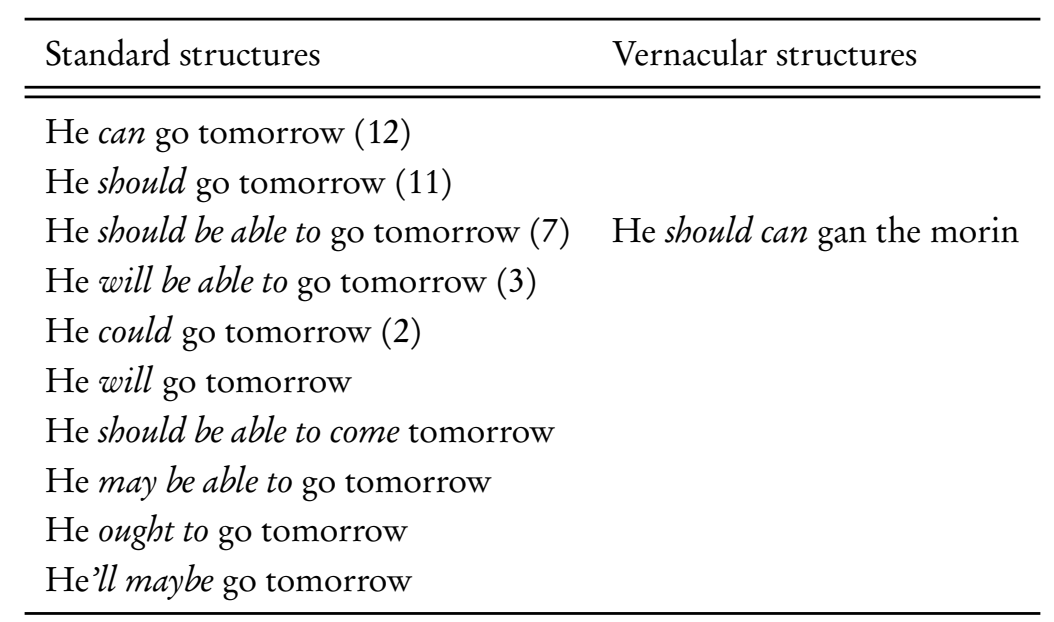

Table 8: He should can go tomorrow.

cific local Scots dialect that does not exceed the South-Eastern part of the Lowlands, unlike the other two alternatives mentioned above. Regarding Standard English constructions, should, with or without additional constructions, remains the favourite modal, proposed 19 times by both genders. It is directly followed by can written eight times by women and four times by men. Other Central and Marginal Modals (Quirk 1985, 137) are proposed only once, such as will, ought to and may.

\section{Conclusion}

The discussion of the 2011 questionnaire that was largely used in Kelso and Jedburgh has shown that a greater number of Standard interpretations were proposed by many respondents, especially women, to replace the modal combinations of the eight sentences. Compared to the 2010 Hawick study, it is a clear upsurge of the Standard, although these three towns are close to one another. Long distance is obviously not a determining factor because rapid changes in the respondents' attitude can be noticed in their use of Multiple Modality in towns located in the same county. Contrary to Hawick, there is generally a lack of participation of male respondents in Kelso and Jedburgh. This has inevitably had an impact on the results obtained, i.e. a greater presence of mainstream structures of replacement over vernacular ones. It is always challenging in questionnaire surveys to reach an equal number of men and women who are ready to complete the study. The behaviour of the respondents when facing such studies keeps varying from town to town. However, a stable maintenance of a minority of MMs in Kelso and Jedburgh is observed. They are still part of the vernacular linguistic culture of the Lowlanders. 


\section{References}

Battistella, Edwin. 1995. "The Syntax of the Double Modal Construction.” Linguistica Atlantica 17: 19-44.

Bour, Anthony. 2010. "Fonctionnement de la Double Modalité en Ecosse: Théorisation et Mise en Pratique d'un Phénomène Dialectal Contemporain, Porteur de Sens." [The Functioning of Double Modality in Scotland: Theorization and Fieldwork of a Contemporary Semantic Dialectal Phenomenon]. Unpublished Master's thesis, Paul Verlaine University, Metz, Lorraine.

Bour, Anthony. 2015. "Multiple Modal Constructions in the Western English-Speaking World." Linguistica Atlantica 34: 49-63.

Bour, Anthony. 2015. "Exotic Multiple Modals: Morphology and Syntax." Scottish Language 34: 14-41.

Brown, Keith, and Martin Millar. 1980. "Auxiliary Verbs in Edinburgh Speech.” Transactions of the Philological Society. 81-133.

Brown, Keith, and Jim Miller. 1982. "Aspect of Scottish English Syntax." English World-Wide 3: 3-17.

Brown, Keith. 1991. "Double Modals in Hawick Scots." In Dialects of English Studies in Grammatical Variation, edited by Peter Trudgill and Jack Chambers, 74-103. London: Routledge.

Butters, Ronald. 1973. "Acceptability Judgments for Double Modals in Southern Dialects." In New Ways of Analyzing Variation in English, edited by Guy Bailey and Roger Shuy, 276-286. Washington, D.C.: Georgetown University Press.

Calvet, Louis-Jean, and Pierre Dumont. 1999. L'Enquête Sociolinguistique. Paris: Editions L'Harmattan.

Chomsky, Noam. 1957. Syntactic Structures. The Hague: Mouton.

Coleman, William. 1975. "Multiple Modals in Southern States English.” PhD diss., Indiana University Bloomington.

De-La-Cruz, Juan. 1995. “The Geography and History of Double Modals in English.” Folia Linguistica Historica XVII/1-2: 75-96.

Di-Paolo, Marianna. 1989. "Double Modals as Single Lexical Items." American Speech 64(3): 195-224.

McClure, Derrick. 2002. Doric, The Dialect of North-East Scotland. Varieties of English Around the World. Amsterdam: John Benjamins Publishing Company.

Mishoe, Margaret, and Michael Montgomery. 1994. "The Pragmatics of Multiple Modal Variation in North and South Carolina." American Speech 69(1): 3-29.

Mufwene, Salikoko. 1994. "Double Modals in American Southern English: How Peculiar Are They?” Contemporary Linguistics 1: 89-104.

Nagle, Stephen. 1989. “Double Modals in Early English.” In Historical Linguistics 1989, Papers from the $9^{\text {th }}$ International Conference on Historical Linguistics, edited by Henk Aertsen and Robert Jeffers, 363-370. Amsterdam: John Benjamins Publishing Company.

Nagle, Stephen. 1994. “The English Double Modal Conspiracy.” Diachronica XI 2: 199-212. Amsterdam: John Benjamins Publishing Company.

Nagle, Stephen, and Michael Montgomery. 1994. "Double Modals in Scotland and the Southern United States: Trans-Atlantic Inheritance or Independent Development?” Folia Linguistica Historica XIV/1-2: 91-107. 
Nagle, Stephen. 1995. “The English Double Modals: Internal or Change?” In Linguistic Change Under Contact Conditions, edited by Jacek Fisiak, 207-216. Berlin: De Gruyter Mouton.

Nagle, Stephen. 1997. "What is Double About Double Modals?" In Language History and Linguistic Modelling. A Festschrift for Jacek Fisiak, edited by Raymond Hickey and Stanislaw Puppel, 1513-1526. Berlin: De Gruyter Mouton.

Quirk, Randolph, Sidney Greenbaum, Geoffrey Leech, and Jan Svarvik. 1985. A Comprehensive Grammar of the English Language. London: Longman.

Rennie, Susan, Matthew Fitt, and Barbara Robertson. 1999. Grammar Broonie: A Guide tae Scots Grammar. Edinburgh, Edinburgh University Press.

Visser, Fredericus T. 1963-1973. An historical Syntax of the English language, Leiden: Brill. 


\section{Questionnaire of 2011 (Sociolinguistic Study)}

\section{Name:}

Forename:

Age:

Gender:

$\mathrm{M} / \mathrm{F}$

Employment:

Workplace:

\section{I}

1) I know I might could and should enjoy myself.

After reading the first sentence evoking a context, try to answer the following questions:

A/ Have you ever heard this kind of underlined structure?

B/ Would you use it yourselves in a similar context? If yes, would you use it regularly, occasionally or rarely?

C/ If not, try to replace it by another one which, according to you, would be more suitable in this context. Do the same for the other seven sentences.
A/
$\mathrm{B} /$
$\mathrm{C} /$

2) He willnae can come.

A/

$\mathrm{B} /$

$\mathrm{C} /$

3) He'll can help us the morn.
A/
B/
$\mathrm{C} /$

4) I was afraid you might couldn't find this address.
A/
B/
$\mathrm{C} /$ 
5) A good machine clipper would could do it in half a day.

A/

$\mathrm{B} /$

$\mathrm{C} /$

6) I think that we should have ought've done that yesterday.
A/
B/
$\mathrm{C} /$

7) He wouldn't could've worked, even if you had asked him.

A/

B/

$\mathrm{C} /$

8) He should can go tomorrow.
A/
$\mathrm{B} /$
$\mathrm{C} /$

II

Choose only one structure (by circling one letter) that, according to you, would be the best choice in the following clauses.

1) $\mathrm{He}$ refuse.
A/ might not can
B/ might not could
C/ used to couldn't
D/ might used to couldn't
E/ another similar construction (in this case, write it in the gap. It must be the same type of grammatical structure as the first four)


2) I thought maybe I better put it (a hearing aid) on or I understand you.
A/ might not couldn't
B/ might couldn't
C/ may not could
D/ might will can't
E/ another similar construction (in this case, write it in the gap)

3) $\mathrm{He} \longrightarrow$ do it for you.
A/ should might better
B/ will might can
C/ 'll should could
D/ 'll might can
E/ another similar construction (in this case, write it in the gap)

4) The girls usually make me some toasted sandwiches but they made any today.
A/ mustn't could've
B/ must not could have
C/ mustn't could have
D/ might not could've
E/ another similar construction (in this case, write it in the gap)

5) If we get a piece of a car, things would be better.
A/ might would
B/ may could
C/ could might
D/ might could
E/ another similar construction (in this case, write it in the gap) 
6) One of our goals be to encourage non-member involvement.
A/ might oughta should
B/ might better
C/ might should oughta
D/ might ought to
E/ another similar construction (in this case, write it in the gap)

7) I think I have me a piece of cake.
A/ may might can
B/ might could
C/ should could
D/ may should ought
E/ another similar construction (in this case, write it in the gap)

8) You have the oil changed.
A/ might ought to should
B/ may should
C/ ought to should
D/ should ought to
E/ another similar construction (in this case, write it in the gap)

\section{III}

Add the question tag you wish to write after each underlined dialectal construction.

1) I might could do that,

2) He must wouldn't steal, ___ ?

3) He'll can do it, , ?

4) He might used to could run the marathon, ?

5) You might could see Uranus if you had a telescope, __ ? 


\section{Additional questions concerning these structures}

IV

In which other contexts do you use them? (Circle one or several letters)
A/ In family
B/ Between friends
C/ At work
D/ Alone
E/ Other suggestions:

V

How often do you use (orally) these types of grammatical constructions? (Circle only one letter)
A/ a lot
B/ often
C/ occasionally
D/ rarely
E/ not at all

You write these types of constructions: (Circle only one letter)
A/ a lot
B/ often
C/ occasionally
D/ rarely
E/ not at all

You write these structures: (Circle only one letter)
A/ When taking notes during meetings or conferences
B/ When leaving a note for a friend
C/ When writing a report
D/ When writing an e-mail to someone
E/ When doing something else (What would it be?): 


\section{To conclude}

Put each of the underlined dialectal constructions in the negative $\&$ in the interrogative.

1) I may can get it out tomorrow.

NEG:

INT:

2) He'll should can come the morn.

NEG:

INT:

3) You should ought to make the rules clear.

NEG:

INT:

4) He might can tell you.

NEG:

INT:

5) The children used to would kind of stay in the background, you know.

NEG:

INT:

Thank you for your cooperation! 